\title{
Penggunaan Limbah Baglog Tiram dan Jenis Nutrisi Terhadap Pakcoy Pada Hidroponik Substrat
}

\author{
Retno Bandriyati Arni Putri ${ }^{1)}$, Trijono Djoko Sulistyo 1), Chairul Anwar²)
}

\begin{abstract}
The increase of oyster mushroom farmers in wonogiri will be impact immediately on increasing waste baglog. One of the utilization is to be medium on hydroponic substrate for growing mustard greens and it will combined with charcoal and various types of nutrients. The research was conducted from October to December 2015 at the Greenhouse C and Laboratory EMPT UNS.the research employed completely random design (CRD) with two factor that is ratio of medium and various types of nutrients. The result of research showed that interaction between ratio of medium and various types affected significantly the parameters of leaf area, leaf fresh weight and leaf biomass. Root fresh weight, root volume, root length and root biomass is only influenced by the type of nutrition with the ab mix is the most good in improving and supplying nutrients
\end{abstract}

Keywords: ratio of medium, $A B$ mix, nutrients available

\section{PENDAHULUAN}

Budidaya jamur tiram berkembang pesat di daerah wonogiri mengakibatkan limbah baglog juga mengalami peningkatan. Semakin menumpuknya limbah akan menimbulkan bau tidak sedap sehingga menimbulkan polusi udara. Tekstur limbah baglog yang lembut dan mampu menahan air sangat cocok dijadikan media pada sistem hidroponik substrat. Penambahan arang kayu cacah diharapkan akan memaksimalkan kinerja limbah baglog sebagai media. Pengujian dilakukan terhadap pakcoy (Brassica rapa) karena memiliki siklus hidup yang relatif singkat selain itu diharapkan akan meningkatkan produksi pakcoy di daerah wonogiri (Warisno 2010). Wiesner (2016) menyatakan bahwa pakcoy adalah tanaman yang cocok dibudidayakan di berbagai daerah karena memiliki toleransi lingkungan lebih baik. Hidroponik tidak terlepas dari nutrisi sebagai penopang kehidupan karena menyediakan unsur hara bagi tanaman oleh karena itu perlu dilakukan penelitian tentang ketepatan jenis nutrisi yang sesuai untuk media limbah baglog tiram. Keberhasilan akan menghasilkan terobosan baru sebagai langkah pemanfaatan limbah yang mengacu pada pertanian terpadu berkelanjutan (Ramsey dan Ungerlaider 2008).

\footnotetext{
1) Lecturer Staff of Study Program of Agrotechnology, Faculty of Agriculture, Sebelas Maret University (UNS) on Surakarta

2) Undergraduate Student of Study Program of Agrotechnology, Faculty of Agriculture, Sebelas Maret University (UNS) on Surakarta

Contact Author: profesionalakun@gmail.com
}

\section{METODE PENELITIAN}

Penelitian dilaksanakan mulai bulan Oktober 2015 sampai bulan Desember 2015 di Rumah Kaca C dan Laboratorium EMPT Fakultas Pertanian Universitas Sebelas Maret Surakarta.

Bahan yang digunakan dalam penelitian ini adalah limbah baglog jamur tiram, arang kayu cacah, bibit pakcoy, nutrisi $A B$ mix, gandasil D dan pupuk organik cair (merek supreme). Alat yang digunakan dalam penelitian ini adalah alat tulis, ember, polybag ukuran 20x20 (cm), timbangan analitik, oven, $\mathrm{pH}$ meter, EC meter, dan TDS.

Rancangan percobaan yang digunakan adalah Rancangan Acak Lengkap (RAL) dengan 2 faktor perlakuan dan diulang sebanyak 3 kali, setiap ulangan menggunakan 2 unit tanaman sehingga didapat 72 unit percobaaan. Faktor pertama adalah perbandingan media yang terdiri dari 4 taraf, yaitu 1:0, 1:1, 2:1, 3:1. Faktor kedua adalah jenis nutrisi yang terdiri atas 3 taraf, yaitu nutrisi $A B$ mix, gandasil d, dan pupuk organik cair (POC).

\section{HASIL DAN PEMBAHASAN}

\section{Jumlah Daun}

Perlakuan media baglog tanpa campuran arang dan nutrisi $A B$ mix mengalami peningkatan terus-menerus dengan kuantitas pertumbuhan daun cukup tinggi pada minggu ke 5 sampai minggu ke 8 , hal tersebut berbeda dengan perlakuan media yang dicampur arang kayu dengan perbandingan 1:1 dan nutrisi pupuk organik cair (POC). Perbedaan dapat dilihat pada Gambar 1 yang menunjukkan garis tidak sama tiap perlakuan yag diujikan. Uji $F$ yang dilakukan (Tabel 1) menjukkan interaksi antar perlakuan pada minggu ke 5 berbeda nyata $(p<0.05)$ sehingga dapat dikatakan bahwa mulai minggu 
ke 5 perlakuan yang diujikan berpengaruh pada pakcoy.

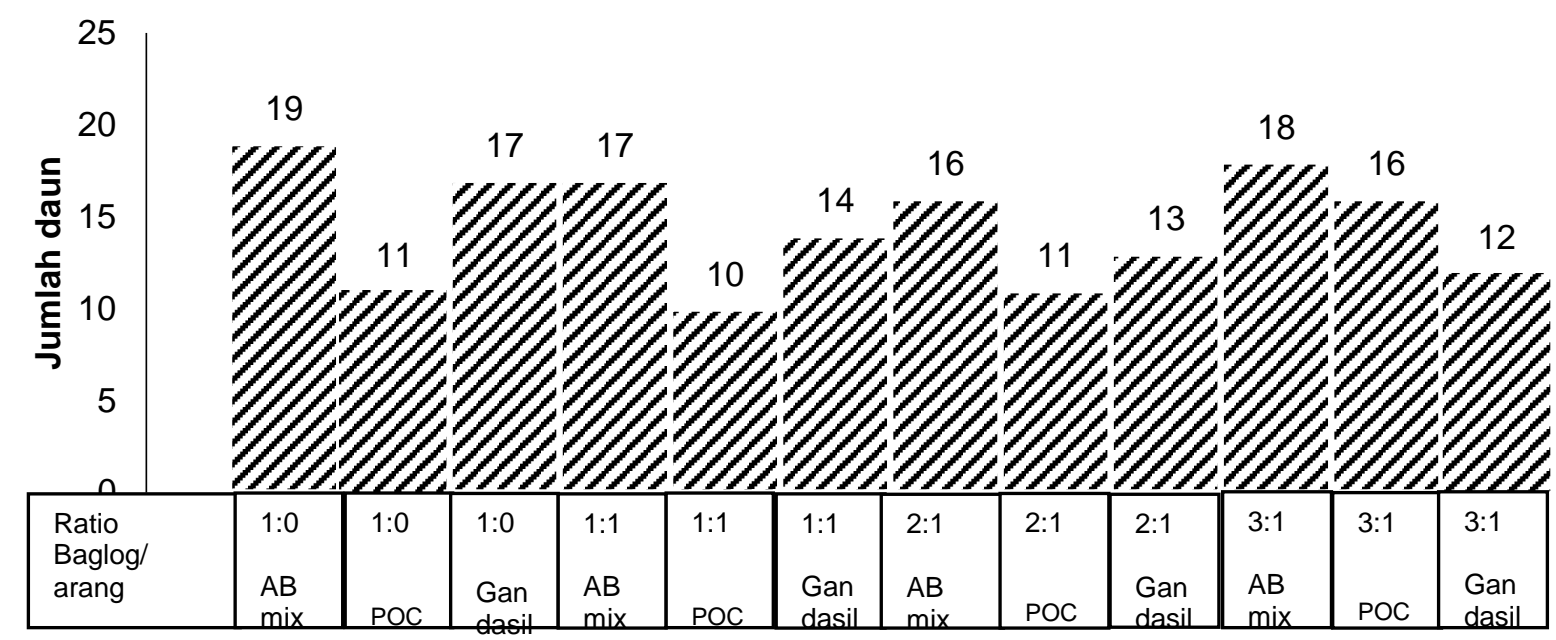

Gambar 1. Pengaruh Penggunaan Limbah Baglog Tiram Dan Jenis Nutrisi Terhadap Luas Daun Pakcoy Minggu ke 8

Tabel 1. Rekapitulasi hasil uji $F$ jumlah daun pakcoy tiap minggu.

\section{Luas Daun}

Perbandingan media yang sama dengan

\begin{tabular}{clllll}
\hline Minggu ke & Media & Nutrisi & \multicolumn{2}{l}{ Interaksijenis nutrisi yang berbeda akan memberikan } \\
\hline 1 & 0,477 & 0,82 & 0,407 & dampak pada luas daun yang berbeda. \\
2 & 0,375 & 0,87 & 0,64 Gambar 2 menunjukkan penggunaan nutrisi \\
3 & 0,204 & 0,06 & 0,551 AB mix maupun gandasil d akan mengalami \\
4 & 0,641 & 0,5 & 0,471 penurunan luas daun ketika perbandingan \\
5 & 0,34 & $0,01^{* *}$ & $0,08^{* *}$ antara media baglog dan arang cacah \\
6 & 0,39 & $0^{* *}$ & $0,02^{* *}$ & ditingkatkan. Hasil tertinggi (Gambar 2) yaitu \\
7 & 0,21 & $0^{* *}$ & $0^{* *}$ & menggunakan media baglog murni tanpa \\
8 & 0,72 & $0^{* *}$ & $0,05^{* *}$ campuran arang cacah.
\end{tabular}

Keterangan : Angka yang diikuti dengan * menunjukkan berbeda nyata pada taraf $0,05 \%$ sedangkan angka yang diikuti dengan ** menunjukkan berbeda sangat nyata pada taraf $0,01 \%$.

Vachirapatama et al. (2011) menyatakan bahwa baglog merupakan media tumbuh jamur tiram yang memiliki komposisi salah satunya adalah pupuk urea. Kandungan NPK pada media dapat memenuhi kebutuhan nutrisi pakcoy pada awal tanam sekitar 2 sampai 3 MST sehingga kekurangan nutrisi dari setiap perlakuan akan dipenuhi, hal ini menyebabkan tidak ada perbedaan nyata dari interaksi antara nutrisi dan media yang diujikan. Setelah tanaman memasuki fase jouvenil maka tanaman memerlukan nutrisi lebih banyak dan dapat dilihat pada Gambar 1, nutrisi $A B$ mix memiliki kemampuan paling baik dalam memenuhi kebutuhan hara tanaman sehingga memiliki jumlah daun paling banyak (Firmansyah 2009).

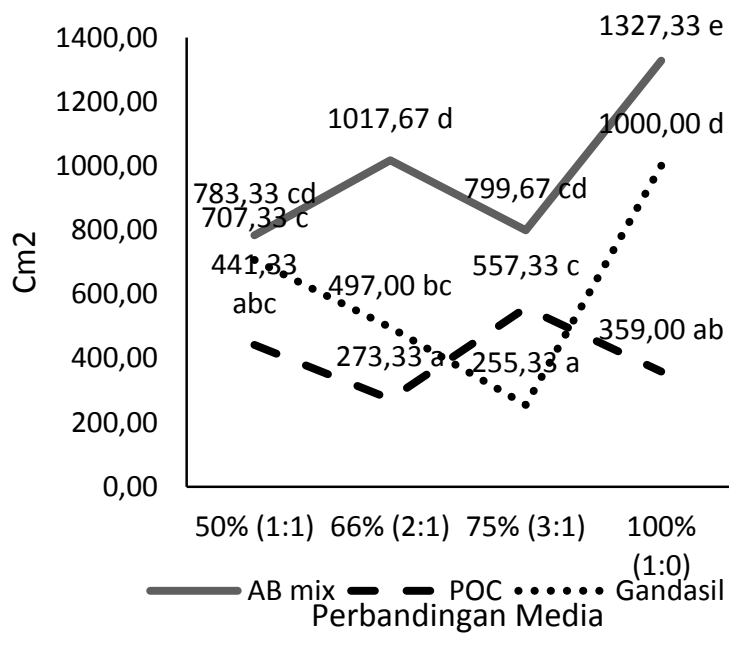

Keterangan: Angka yang diikuti huruf yang sama menunjukkan tidak beda nyata pada uji Duncan taraf $5 \%$.

Gambar 2. Grafik interaksi antara perbandingan media dengan nutrisi yang diberikan terhadap luas daun pakcoy. 
Penambahan arang kayu cacah akan membuat tekstur media lebih berongga dan juga mengurangi bagian media yang mampu menahan dan menyimpan air. Nutrisi yang diberikan akan langsung terbuang keluar media, keadaan ini kurang cocok dengan jenis nutrisi $A B$ mix dan gandasil $D$ yang memmiliki karakter nutrisi siap pakai (Novella et al. 2008). Perbandingan media tanpa arang akan menciptakan kondisi tektur yang sangat lembut cenderung padat dan dapat dikatakan media tersebut memiliki kandungan udara sangat sedikit karena pori makro tertutupi air. Keadaan ini kurang cocok dengan penggunaan POC yang memanfaatkan bakteri untuk proses penyediaan hara. Keadaan yang an aerob akan mempersulit bakteri untuk melakukan dekomposisi (Silvina 2008).

\section{Berat Basah Daun}

Semakin tinggi perbandingan antara baglog dan arang tidak menunjukkan berat basah daun yang semakin tinggi (Gambar 3). AB mix dengan pupuk organik cair cenderung tidak sama dengan ditunjukkan perbandingan media $100 \%$ baglog dan penggunaan nutrisi $A B$ mix memiliki nilai berat basah daun paling tinggi, sedangkan pada pupuk organik cair perbandingan media 3:1 menunjukkan hasil paling tinggi. Gandasil D yang diberikan memiliki pola yang cenderung sama dengan pupuk $A B$ mix.

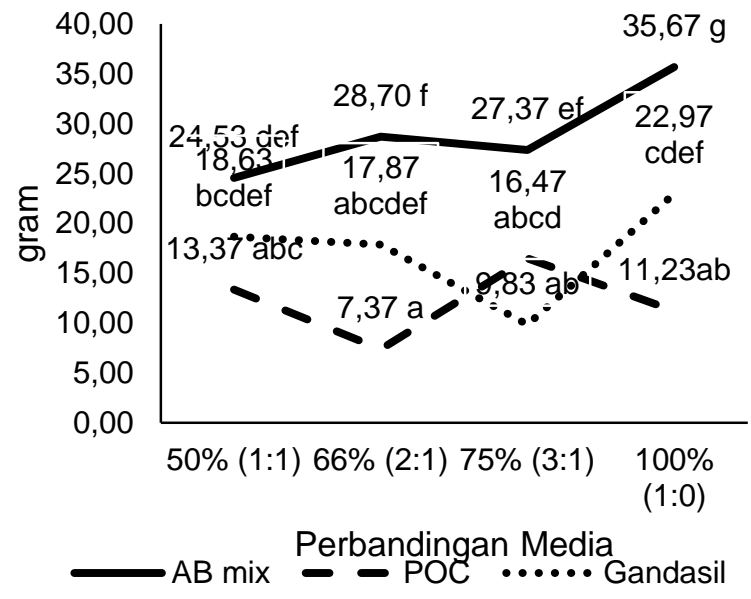

Keterangan: Angka yang diikuti huruf yang sama menunjukkan tidak beda nyata pada uji Duncan taraf $5 \%$.

Gambar 3. Grafik interaksi antara perbandingan media dengan nutrisi yang diberikan terhadap berat basah daun pakcoy.

Perbedaan berat basah daun pada setiap perlakuan dapat dipengaruhi oleh laju evapotranspirasi dan laju absorbsi dari tanaman pakcoy. Tanaman yang defisit air akan menurunkan berat basah tanaman tersebut hal ini disebabkan oleh laju evapotranspirasi melebihi laju absorbsi air oleh tanaman atau disebut cekaman kekeringan (Bhattarai et al. 2008). $A B$ mix adalah nutrisi khusus yang memiliki kandungan unsur hara siap pakai, berbeda dengan POC. POC memerlukan waktu mineralisasi maupun immobilisasi lewat dekomposisi untuk menjadikan usur hara yang terkandung menjadi siap pakai tanaman. Keadaan ini akan berjalan baik pada media tumbuh yang memiliki porositas yang baik yaitu porositas antara makro pori maupun mikro pori adalah seimbang (Hendriyani 2009). Penelitian yang dilakukan David dan Tom (2016) membuktikan bahwa keadaan media yang tergenang akan mempengaruhi ketersediaan nutrisi bagi tanaman.

\section{Berat Kering Daun}

Interaksi antara ratio media dengan nutrisi dapat dilihat pada Gambar 4 yang menunjukkan semakin banyak perbadningan media tidak menjamin semakin berat kering daun yang dihasilkan. $A B$ mix memiliki unsur $\mathrm{N}$ paling tinggi sehingga memiliki berat kering daun paling tinggi. Pupuk organik cair cenderung lebih rendah dikarenakan kandungan $\mathrm{N}$ pada pupuk organik cair juga tergolong rendah $\mathrm{N}$ tersedia pada media memerlukan waktu sebagai proses dekomposisi dan mineralisasi.

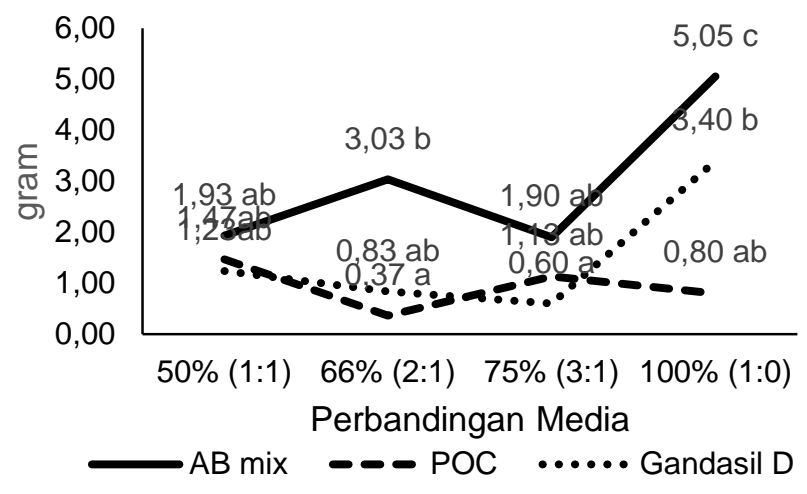

Keterangan: Angka yang diikuti huruf yang sama menunjukkan tidak beda nyata pada uji Duncan taraf $5 \%$.

Gambar 4. Grafik interaksi antara perbandingan media dengan nutrisi yang diberikan terhadap berat kering daun pakcoy.

Protoplasma adalah suatu zat yang sangat kompleks, terdiri dari 85 - 90 persen air (menurut berat segarnya) dan sisanya terdiri dari zat-zat organik dan anorganik. 40-50\% protoplasma tersusun dari senyawa yang mengandung $\mathrm{N}$. Semakin tercukupinya kebutuhan $\mathrm{N}$ maka akan semakin banyak protoplasma yang dibentuk 
sehingga akan meningkatkan berat segar tanaman secara nyata. AB mix memiliki unsur $\mathrm{N}$ paling tinggi sehingga memiliki berat kering daun paling tinggi. Pupuk organik cair cenderung lebih rendah dikarenakan kandungan $\mathrm{N}$ pada pupuk organik cair bukanlah jenis $\mathrm{N}$ tersedia (Lakitan 2004).

\section{Berat Basah Akar}

Hasil penelitian menunjukkan bahwa penggunaan nutrisi $A B$ mix lebih baik (Gambar 5) dalam menumbuhkan akar dari pada nutrisi pupuk organik cair dengan gandasil D terhadap berat basah akar berdasarkan analisis ragam ( $p$ $<0.05)$. Kandungan fosfor pada $A B$ mix paling tinggi dibandingkan dengan $\mathrm{POC}$ dan gandasil D.

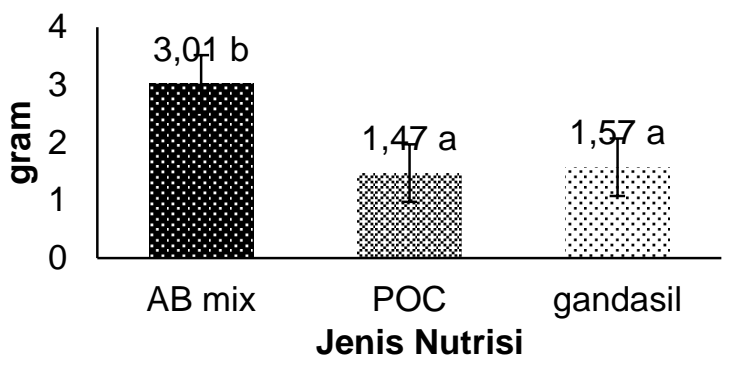

Keterangan : Angka-angka yang diikuti huruf yang sama menunjukkan tidak berbeda nyata pada uji DMR taraf $5 \%$

Gambar 5. Perlakuan jenis nutrisi terhadap berat basah akar.

Menurut Thuy et al. (2010) tanaman yang dipupuk fosfor mengembangkan lebih banyak akar dibandingkan tanaman yang tidak dipupuk fosfor. Kandungan fosfor pada $A B$ mix paling tinggi dibandingkan dengan POC dan gandasil D. Kebutuhan fosfor untuk tanaman pakcoy adalah $0,75 \%$. Faktor lain adalah karena pupuk AB mix adalah pupuk khusus hidroponik sehingga unsur harannya siap diserap oleh akar. POC adalah pupuk organik yang memang merlukan proses perombakan untuk menyediakan fosfor tersedia (Akasiska et al 2014).

\section{Volume Akar}

Analisis ragam $(p<0.05)$ yang dilakukan menunjukkan nutrisi yang diberikan mempengaruhi volume akar pakcoy dengan nutrisi $A B$ mix memiliki efektifitas paling tinggi dalam menunjang pertumbuhan akar sehingga mempengaruhi volume akar sedangkan pupuk organik cair tergolong sedang jika dibandingkan dengan pupuk gandasil (Gambar 6).

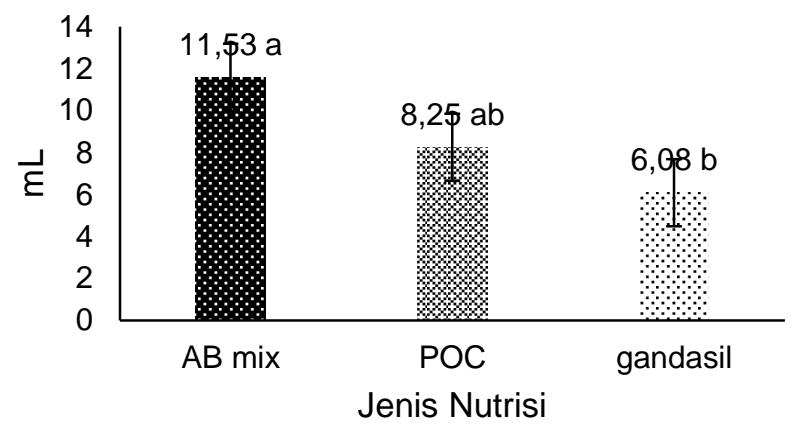

Keterangan : Angka-angka yang diikuti huruf yang sama menunjukkan tidak berbeda nyata pada uji DMR taraf $5 \%$

Gambar 6. Perlakuan jenis nutrisi terhadap volume akar pakcoy.

Volume akar dipengaruhi oleh tingkat distribusi akar, ketersediaan hara dan air. Volume akar dapat menjadi parameter untuk mengukur jangkauan akar dalam memperoleh hara dan air. Volume akar dipengaruhi oleh dua unsur penting yang membangun jaringan pada akar yaitu Fosfor (P) dan kalsium (Ca). Menurut Anas (2004), bahwa kalsium (Ca) berpengaruh pasa meristem atau titik tumbuh di ujuang akar sehingga volume akar bertambah yang akhirnya dapat memacu pertumbuhan. Kekurangan $\mathrm{Ca}$ mungkin menyebabkan sistem translokasi yang lemah, organisasi sel yang tidak baik, dan hilangnya permeabilitas sel (Sumoharjo dan Maidie 2013).

\section{Panjang Akar}

Analisis ragam menunjukkan tidak adanya interaksi ataupun pengaruh dari perlakuan pada panjang akar pakcoy. Hasil ini membuktikan bahwa perbandingan media antara limbah baglog tiram dan juga arang cacah dianggap sama artinya, akar dapat tumbuh dengan baik tanpa atau dengan tambahan arang cacah. Media limbah baglog tiram mampu menahan air dan unsur hara dengan baik dan ditunjang tekstru yang lembut. Akar mampu melakukan penetrasi dengan baik pada berbagai media yang diujikan. Roosta dan Afsharipoor (2012) menyatakan bahwa tanaman yang mengembangkan sistem perakaran yang dalam dapat mengekstrak air di lapisan tanah yang lebih dalam. Peningkatan panjang merupakan respons morfologi yang penting dalam proses adaptasi tanaman terhadap kekurangan air (Budiasih 2009).

\section{Berat Kering Akar}

$A B$ mix memiliki efektifitas paling tinggi dalam menunjang pertumbuhan akar sehingga mempengaruhi berat kering akar sebagai hasil 
fotosintat bersih sedangkan pupuk organik cair tergolong sedang jika dibandingkan dengan pupuk gandasil (Gambar 7). Analisis ragam ( $p<$ 0.05 ) yang dilakukan menunjukkan nutrisi $A B$ mix memiliki pengaruh palign baik.

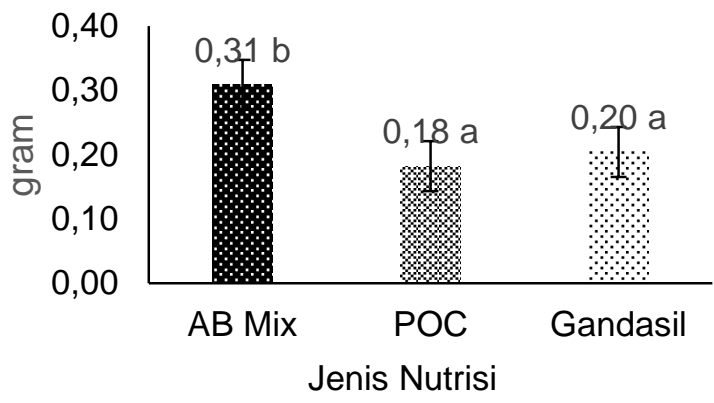

Keterangan : Angka-angka yang diikuti huruf yang sama menunjukkan tidak berbeda nyata pada uji DMR taraf $5 \%$

Gambar 7. Perlakuan jenis nutrisi terhadap volume akar pakcoy.

Vachirapatama dan Jirakiattikul (2008) menyatakan bahwa kalsium berpengaruh pada meristem atau titik tumbuh di ujuang akar sehingga volume akar bertambah yang akhirnya dapat memacu pertumbuhan. Unsur fosfor akan mengembangkan pertumbuhan akar lebih baik sehingga menghasilkan berat kering akar yang optimal. Berat basah akar terdiri dari hasil fotosintesis dan juga kandungan air sehingga ketika berat kering naik maka berat basah juga mengalami kenaikan (Akasiska et al. 2014).

\section{KESIMPULAN DAN SARAN}

\section{Kesimpulan}

Kesimpulan yang dapat diambil dari penelitian mengenai Penggunaan Limbah Baglog Tiram dan Jenis Nutrisi terhadap Pakcoy pada Hidroponik Substrat adalah :

1. Limbah baglog tiram dapat digunakan sebagai salah satu alternatif media hidroponik substrat.

2. Terjadi interaksi antara perbandingan media dengan jenis nutrisi terhadap jumlah daun, luas daun, berat basah daun dan berat kering daun pakcoy.

3. Nutrisi $A B$ mix menunjukkan hasil yang paling baik pada semua variabel kecuali pada variabel panjang akar.

\section{Saran}

Saran yang diberikan untuk penelitian mengenai Penggunaan Limbah Baglog Tiram dan Jenis Nutrisi terhadap Pakcoy pada Hidroponik Substrat selanjutnya adalah:

1. Perlunya pengujian kandungan hara media setelah pemanenan
2. Perlunya pengamatan volume media sebelum penanaman dan sesudah pemanenan terkait kecepatan dekomposisi media

3. Untuk penelitian selanjutnya sebaiknya menggunakan tanaman yang mencapai fase generatif untuk masuk kriteria panen.

\section{DAFTAR PUSTAKA}

Akasiska, R., Riyo, S., Siswadi, 2014, Pengaruh Konsentrasi Nutrisi Dan Media Tanam Terhadap Pertumbuhan Dan Hasil Sawi Pakcoy (Brassica parachinensis) Sistem Hidroponik Vertikultur, Inovasi Pertanian, 13(2) : 46-62.

Anas, DS., Yunni, K. 2004, Pengaruh Volume dan Jenis Media Tanam pada Pertumbuhan dan Hasil Tanaman Selada Dalam Teknologi Hidroponik Sistem Trapung, Bul Agron 32(3) : 16-21, ISSN. 2085-2916.

Bhattarai, SP., Clemence S., David, J. Midmore. Oxygation of the Rockwool Substrate for Hydroponics, Aquaponics Jomnal (2) : 1-5. www.aquaponicsjournal.com

Budiasih, 2009, Respon Tanaman Padi Gogo Terhadap Cekaman Kekeringan, Ganec Swara Edisi Khusus 3(3) : 22-27. http://ejournal.unsrat.ac.id/index.php/bioslog os/article.

David E., Tom H. 2016, A new wood fibre substrate for hydroponic tomato and pepper crops, Plant Sci (1) : 1-6. www.nrcresearchpress.com by 202.67.41.21

Firmansyah, F., Tino, MA., Aos, MA. 2009, Pengaruh Umur Pindah Tanam Bibit dan Populasi Tanaman terhadap Hasil dan Kualitas Sayuran Pakcoy (Brassica campestris L. Chinensis group) yang Ditanaman dalam Naungan Kasa di Dataran Medium Agrikultura 20(3) : 216-224. http://journals.unpad.ac.id/agrikultura/article.

Hendriyani, IS., N. Setiari, 2009, Kandungan Klorofil dan Pertumbuhan Kacang Panjang (Vigna sinensis) pada Tingkat Penyediaan Air yang Berbeda, J Sains nad Mat 17(3) : 145-150, ISSN 0854-0675.

Lakitan, B. 2004, Dasar-Dasar Fisiologi Tumbuhan, Jakarta : Raja Grafindo Persada.

Novella, BM., Luiz, JA., Antonio, DB. et al. 2008 Concentration of nutrient solution in the hydroponic production of potato minitubers, Ciencia Rural, 38(6) : 1529-1533, ISSN 0103-8478. 
Ramsey, W., Ungerlaider, A. 2008, Hybrid composite hydroponic substrate system (1) : 1-14, Hak paten US20080034653 A1.

Roosta, HR., Afsharipoor, S. 2012, Effects Of Different Cultivation Media On Vegetative Growth, Ecophysiological Traits And Nutrients Concentration In Strawberry Under Hydroponic And Aquaponic Cultivation Systems, Adva Environ Biol, 6(2) : 543-555, ISSN 1995-0756.

Thuy Ngo Diem Trang, Hans-Henrik Schierup, Hans Brix, 2013, Leaf vegetables for use in integrated hydroponics and aquaculture systems: Effects of root flooding on growth, mineral composition and nutrient uptake. Afri J Biotechn 9(27) : 4186-4196, ISSN 16845315.

Silvina, R., Syalfina, 2008, Penggunaan Berbagai Medium Tanam dan Konsentrasi Pupuk Organik Cair pada Pertumbuhan dan Produksi Mentimun Jepang (Cucumis sativus) Secara Hidroponik, Sagu, 7(1) : hal 7-12, ISSN: 1412-4424.

Sumoharjo, Maidie, A. 2013, Evaluation on Biofilter in Recirculating Integrated MultiTrophic Aquaculture, Internat, J Sci and Eng, 4(2) : 80-85, DOI: 10.12777/ijse.

Vachirapatama, N., Jirakiattikul, Y. 2008, Effect of vanadium on growth of Chinese green mustard (Brassica campestris ssp. chinensis var. parachinensis) under substrate culture, Songklanakarin J Sci Technol, 30(4) : 427431, http://www.sjst.psu.ac.th.

Vachirapatama, N., Jirakiattikul, Y., Greg Dicinoski et al. 2011, Effect of vanadium on plant growth and it accumulation in plant tissues, Songklanakarin J Sci, Technol, 33(3) : 255-261, http://www.sjst.psu.ac.th.

Warisno, Kres D. 2010, Menabur Jamur, Menuai Rupiah, Jakarta : Gramedia.

Wiesner, M., Rita Zrenner, Angelika Krumbein et al. 2016, Genotypic Variation of the Glucosinolate Profile in Pak Choi (Brassica rapa ssp. chinensis), (61), J Agric Food Chem, 1943-1953, Doi: 10.1021. 